\title{
“CIVILIZAR O RURAL?": MEMÓRIAS DE PRÁTICAS EM TORNO DA AULA PÚBLICA MUNICIPAL NO MORRO DOS BOIS - NOVO HAMBURGO/RS $(1933-1952)^{1}$
}

\author{
José Edimar de Souza ${ }^{2}$ \\ UNISINOS- CAPES/Proex
}

\section{RESUMO}

Este estudo analisa narrativas de dois professores, cujas memórias ajudam a compreender como foram se processando os acontecimentos em torno das instituições escolares e das práticas culturais, nos tempos da Aula Pública do Morro dos Bois, em torno dos anos $30 \mathrm{e}$ 50 do século XX. Halbwachs, Chartier e Viñao Frago, entre outros, auxiliam na articulação entre memória e contexto sócio-histórico analisado sob a ótica da História Cultural. O conjunto de indicadores empíricos evidencia um saber incorporado ao fazer docente naquela comunidade - de fato, um legado de práticas que se preservam até os dias de hoje - em especial originário da família Scherer. Ao desenvolver os procedimentos analíticos, percebem-se também limites e possibilidades no uso da memória. Entre as conclusões, ainda permanece uma questão: A escola dos "Scherer" representou uma possibilidade de civilizar os colonos? Em outras palavras, mesmo que não de modo intencional, teria sido um espaço de cultura de civilidade, forjada pelo matiz do momento histórico que vivia o país entre os anos 1930 e 1950, cuja modernização e urbanização ocupavam lugar de destaque e havia a pretensão de imprimir na sociedade uma moral cristã sob a ótica do espírito nacionalista?

Palavras-chave: Memória; Práticas Culturais; Ensino Rural.

\section{"CIVILIZE RURAL?": MEMORIES OF PRACTICES AROUND THE PUBLIC CLASS HALL OF THE MORRO BOIS - NOVO HAMBURGO/ RS (1933-1952)}

\begin{abstract}
This study analyzes narratives of two teachers, whose memories help us understand how the events were taking place around the schools and cultural practices in times of Public Class Morro dos Bois, around 30 and 50 years of the twentieth century. Halbwachs, Chartier and Viñao Frago, among others, assist in linking memory and socio-historical context analyzed from the perspective of cultural history. The set of empirical indicators reflects a knowing incorporated to make teaching in the community - in fact, a legacy of practices that are preserved until the present day - especially original family Scherer. In developing the analytical procedures are perceived limits and possibilities also in memory usage. Among the conclusions, still remains a question: The school of "Scherer" represented an opportunity to civilize the colonists? In other words, even if not intentionally, would have been a space for culture of civility, forged by the hue of the historical moment that the country lived between the years 1930 and 1950, whose modernization and urbanization occupied a prominent place and had the intention of print a moral Christian society from the perspective of nationalist spirit?
\end{abstract}

Keywords: Memory. Cultural Practices. Rural Education. 


\section{Introdução}

Este texto expõe reflexões iniciais, construídas a partir da investigação de doutorado, em curso no Programa de Pós-Graduação em Educação da UNISINOS. Analisa memórias de práticas pedagógicas de dois professores: Sérgio e Márcia Scherer ${ }^{3}$ cuja trajetória docente desenvolveu-se na localidade do Morro dos Bois (no bairro rural de Lomba Grande) em Novo Hamburgo-RS. Dessa forma, entende-se a memória no sentido que atenta Halbwachs e percorrem-se os fragmentos que permitiram reconstruir uma história da escola isolada Tiradentes, atualmente, chamada EMEF (Escola Municipal de Ensino Fundamental) Tiradentes.

Novo Hamburgo, em destaque na figura 1, é um município brasileiro do estado do Rio Grande do Sul localizado na micro-região do Vale dos Sinos. Ocupa uma área de $222,35 \mathrm{~km}^{2}$ e tem uma população de aproximadamente 240.000 habitantes. Limita-se com Campo Bom, Dois Irmãos, Estância Velha Gravataí, Ivoti, São Leopoldo, Sapiranga, Sapucaia do Sul e Taquara. (SOUZA, 2012). Situado aproximadamente a $40 \mathrm{~km}$ da capital Porto Alegre, representa uma das maiores redes municipais de ensino com aproximadamente 26.000 alunos e 1.600 professores em 76 escolas de Educação Infantil e Ensino Fundamental. (ROCHA, 2012).

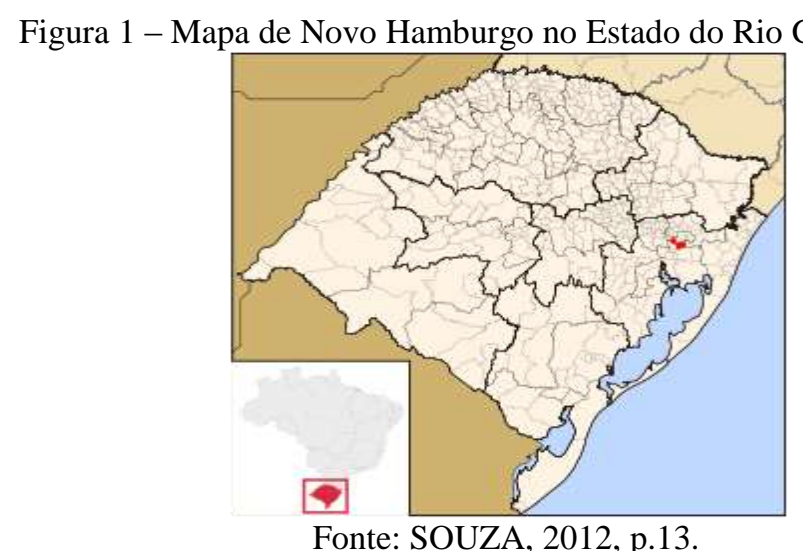

No espaço rural $^{4}$, no bairro Lomba Grande, existem sete escolas, sendo a EMEF (Escola Municipal de Ensino Fundamental) Tiradentes e EMEF Bento Gonçalves ainda consideradas isoladas, ou seja, escolas remanescentes ${ }^{5}$ que funcionam em regime docente multisseriado, em um único turno, sob a gestão administrativa de outras escolas ${ }^{6}$.

Escola Multisseriada ${ }^{7}$, de mestre-único, unitarista ou isolada são termos atribuídos às escolas de primeiras letras que a partir da segunda metade do século XIX até os dias de hoje, para muitas comunidades rurais representaram a forma possível para o contato com algum tipo de escolarização.

Este texto está organizado em quatro partes, além da introdução. Inicialmente apresenta-se a escolha teórica que orientou análise, bem como susta a opção metodológica de trabalho com a História Oral. Os outros tópicos apresentam o cenário de contexto do ensino no município de Novo Hamburgo, principalmente na primeira metade do século XX e neste sentido, em seguida, as primeiras elaborações sobre as práticas pedagógicas em uma escola isolada rural. As considerações finais são estabelecidas a partir de conclusões provisórias do que foi possível analisar até o momento. 


\section{Escolhas Teóricas e Metodológicas}

Entendendo que a construção do conhecimento representa uma possibilidade explicativa sobre a realidade estudada, dados os referenciais teóricos e metodológicos, porque "[...] a ciência atual não busca mais uma visão do mundo total explicativa, o que produz é parcial e provisório. [...] confronta-se com uma realidade incerta, de fronteiras imprecisas e mutáveis, [...]”. (BALANDIER, 1997, p. 10). Dessa forma, o conhecimento expressa a comunhão do saber entre as pessoas, através da inquietação do não saber, síntese das experiências e práticas construídas em um percurso de vida produzindo questionamentos e novos campos conceituais.

Quanto aos estudos sobre a escola pública primária no Brasil, Souza (2006), verifica um renovado interesse dos historiadores da educação brasileira pela história do ensino primário, no entanto, a autora chama atenção para sua problematização, no seu ponto de vista ela deve contemplar o âmbito das práticas, do modelo de organização escolar e do funcionamento interno das instituições educativas. "Para tanto, tornam-se imprescindíveis os estudos em cultura escolar que possam explicitar as diversas dimensões do funcionamento interno da escola em sua relação com a sociedade [...].”. (SOUZA, 2006, p.111).

Compartilha-se, nesta pesquisa, a perspectiva da história cultural de Roger Chartier, quando ele afirma que essa abordagem tem "[...] por principal objeto identificar o modo como em diferentes lugares e momentos uma determinada realidade social é construída, pensada e dada a ler". (CHARTIER, 2002, p. 16-17). E também quando o autor esclarece:

As percepções do social não são de forma alguma discursos neutros: produzem estratégias e práticas (sociais, escolares, políticas) que tendem a impor uma autoridade à custa de outros, por elas menosprezada, a legitimar um projecto reformador ou justificar, para os próprios indivíduos, as suas escolhas e condutas [...]. (CHARTIER, 2002, p. 17).

As pesquisas sobre culturas e práticas escolares, desde o final dos anos 90 do século $\mathrm{XX}$, tem divisado pesquisadores, principalmente quanto à seguinte questão: a escola seria produtora de uma cultura própria? Destaca-se, neste sentido, os estudos realizados por:

[...] Diana Vidal enfrenta a discussão acerca dos 'usos e abusos' das concepções sobre cultura escolar [...] convoca alguns autores [...] dentre eles, André Chervel (1990), que enfatiza a singularidade, a originalidade da cultura escolar e a capacidade inventiva do sistema escolar [...]. (CURY, 2010, p. 44).

Entendendo que as práticas são criadoras de formas apropriadas pelas quais os sujeitos "inventam uma cultura escolar", questiona-se: a escola isolada em Lomba Grande colonizou e civilizou o rural? As memórias de práticas pedagógicas dos professores Sérgio e Márcia remetem a quais possibilidades analíticas?

Quanto aos estudos de memória, é necessário registrar que não sendo a História, é um dos seus indícios, que pode ser transformado em documentos e de que se serve o historiador para produzir leituras do passado, do vivido pelos indivíduos, daquilo de que se lembram e se esquecem a um só tempo, produzindo no presente determinadas versões do passado.

Halbwachs aponta que as lembranças podem, a partir da vivência em grupo, ser reconstruídas ou simuladas. Podemos criar representações do passado assentadas na 
percepção de outras pessoas, no que imaginamos ter acontecido ou pela internalização de representações de uma memória histórica. A lembrança, de acordo com Halbwachs, "é uma imagem engajada em outras imagens" (2006, p. 77).

Distante de agregar a este trabalho um valor que recupere memórias de todo um percurso das "Aulas" que aconteciam em Novo Hamburgo, para isso precisaria de infinitas páginas, as lembranças dos primórdios de práticas do ensino rural neste município, aqui registradas, remetem às relações que a memória social proporciona na sua complexidade (HALBWACHS, 2006). Tomson (1997) e Amado (1995) argumentam que a experiência como prática vivida, que remete a concretude da experiência de um indivíduo ou de um grupo social, constitui um substrato da memória que se reelabora constantemente, ou seja, nunca termina. As narrativas, segundo Amado (1995), retratam um cenário considerando que ao trazer o passado até o presente, o recria-se à luz do presente, ao mesmo tempo em que o projeta-se no futuro. Stephanou (2011) complementa refletindo que o que lembramos/esquecemos não é uma realidade passada e ainda tangível, tampouco acessível na imediatez da narrativa. Escrevemos e dizemos o que pensamos ter vivido, o que pensamos ter sentido, o que imaginamos ter experimentado.

Aplica-se nesta investigação, além da história oral a análise documental sob a ótica da História Cultural (CHARTIER, 2002). Dessa forma, a cultura representa um conjunto de significados partilhados e construídos para compreender e conhecer um pouco sobre a evidência das instituições escolares, a evidência da Aula nas comunidades rurais como prática que caracteriza o contexto da educação no Brasil no início do século XX.

De acordo com o autor acima citado é importante lembrar que práticas são criadoras de "usos ou de representações" que não são, de forma alguma, redutíveis à vontade dos problemas de discursos e de normas, encontram-se na construção de uma cultura. Assim, o modo como professores desenvolveram e fizeram opção de suas práticas sociais figuraram como "[...] modos de viver, trabalhar, morar [...] Assim, a cultura é sempre tomada como expressão de todas as dimensões da vida, incluindo valores, sentimentos, emoções, hábitos [...]" (OLIVEIRA, 2004, p. 272). Portanto, no campo de análise, é o aspecto da constituição da docência, bem como ações do cotidiano no contexto histórico-cultural que devem ser considerados.

A cultura local revelou uma forma de organização coletiva que incluiu o rural como lugar de pertencimento frente às representações postas pelo mundo social urbano. Para esses professores pertencer ao campo representou "[...] identidade construída [...] mostrada e reconhecida [...]" pela força da oralidade, dos discursos que denunciaram à margem imposta por uma organização baseada na cidade (CHARTIER, 2002, p. 11). A imposição do mundo social urbano contribuiu para fortalecer a representação construída de que no espaço rural se desenvolveram os "ofícios de valor menor", ou seja, a agricultura em contraste com o progresso impresso pela modernidade (BURKE, 2005, p. 50).

Com Thompson (1992) aprende-se que a abordagem da História, a partir de evidências orais, permite ressaltar elementos que, de outro modo, por outras estratégias investigativas, seriam inacessíveis. Vale frisar que neste estudo as entrevistas transcritas são tomadas como documento e servem para refletir e compreender o passado, ao lado de documentos escritos, imagens e demais tipos de registro encontrados ao longo da investigação.

A partir da análise documental buscou-se identificar o modo como em diferentes lugares e momentos uma determinada realidade social é construída a partir do entrecruzamento de aspectos que emergiram na construção dos documentos orais e na organização das informações de diferentes naturezas (documentos orais, escritos e icnográficos). São as "lentes", definidas pelo historiador, que a partir de memórias 
(documentos construídos) vão fazer o desenho da história, reconstruindo, involuntariamente omitindo partes, ou extrapolando fatos, ou mesmo contando fragmentos de um todo maior.

\section{O cenário do contexto de pesquisa: Novo Hamburgo na primeira metade do século $\mathbf{X X}$}

A história de escolarização no município antes da emancipação 1927 vincula-se a história da educação de São Leopoldo ${ }^{8}$. Novo Hamburgo, $2^{\circ}$ Distrito de São Leopoldo, registra uma forma artesanal de organização do ensino até a década de 1950. Entendo-a deste modo, pois a escolarização se dava pela articulação entre a comunidade e a pequena participação e investimento na educação, por parte do estado, como ente público. Em Lomba Grande, até 1940 a localidade esteve sob a jurisdição de São Leopoldo, como $3^{\circ}$ Distrito.

Na primeira metade do século XX, principalmente a partir de 1915, ocorreram campanhas e realizações através da educação e que pretendiam combater o analfabetismo; difundir a educação primária; defender o patriotismo; entre outras ações que primavam pela difusão da educação no Brasil. Essa foi à característica básica do entusiasmo pela educação. Dessa forma, educar o povo seria primordial para solucionar as mazelas da desigualdade, "modernizar e civilizar o homem", pela educação elevaria o nível cultural e social do País.

No contexto educacional brasileiro, com o advento da República, abriu-se um processo de mudanças estruturais que se pautava na consolidação do trabalho assalariado e melhoramentos urbanos aliados ao início da industrialização. No que se refere ao espaço rural: o Brasil passou de uma sociedade eminentemente agrária a uma sociedade industrial, a cidade assumindo a posição de guia, de modelo dos paradigmas culturais e sociais. Almeida (2007) argumenta que as mudanças econômicas e sociais promoveram transfigurações identitárias e, portanto, afirmou-se uma tendência de construção de identidades urbanas, associando a cidade ao status de progresso.

A questão fundamental da escola continuava sendo de saber ler, escrever e contar. A função da instrução salientava-se frente aos novos paradigmas que se projetavam na ótica da formação geral e do desenvolvimento humano como sujeito pátrio, ativo e atuante. (GHIRARDELLI JUNIOR, 2009).

A educação rural foi vista como um instrumento capaz de formar, de modelar um cidadão adaptado ao seu meio de origem, mas lapidado pelo conhecimento científico endossado pelo meio urbano. Ou seja, a cidade é quem apresentava as diretrizes para formar o homem do campo, partindo daí, os ensinamentos capazes de orientá-lo, civilizá-lo a bem viver nas suas atividades. A escolarização deveria preparar e instrumentalizar o homem rural para enfrentar as mudanças sociais e econômicas. Dessa forma, o sujeito do campo poderia participar e compreender as ideias de progresso e modernidade que emergiam no país.

Em Lomba Grande, a história da educação se relaciona à sensibilidade da comunidade e das famílias, dos primeiros colonos alemães que chegaram em 1824 e que cediam compartimentos em suas residências para que fossem ministradas Aulas. (SOUZA, 2012). O professor, em alguns casos, também era oriundo da sua comunidade, que apesar da instrução mínima, na ausência de um mestre graduado (professor diplomado, dadas às dificuldades do meio físico), desempenhavam a docência, como professores leigos, superando inclusive as dificuldades de falta de material didático, condicionando-se aos soldos provenientes das famílias. 
As Aulas Públicas ${ }^{9}$ eram instaladas quando existia o corpo docente. Havendo um professor, que era alocado segundo a demanda de matrículas, considerando o número de crianças em idade escolar, sem atendimento ou por interesses políticos, os recursos eram providenciados. A existência das Aulas estava condicionada ao professor, caso ele mudasse de residência, não vinha outro para substituí-lo, transladava consigo sua aula. Werle (2005) e Grazziotin (2008) indicam que as Aulas receberam também as denominações de Aulas Isoladas ${ }^{10}$ ou Avulsas.

\section{Casa, Escola e Armazém: Fragmentos de memórias reconstruindo práticas de uma escola isolada}

Para Almeida (2006) a reconfiguração da sociedade brasileira que se estruturava a partir da República, se desejava progressista e esclarecida, com o potencial de regeneração nacional, havia a crença numa visão de escola doméstica, que cuida, ampara, ama e educa. No período de nossa história, designado de República Velha, há considerável incremento das escolas públicas. O ensino privado, contudo, vai experimentar seu período áureo, sob a égide do Positivismo e seu peculiar posicionamento em relação ao ensino. O período foi, por outro lado, tempo de gestação de nacionalismo que se faria sentir de modo especial na Era Vargas, quando o Estado totalitário, criando inimigos para se manter no poder, se lançou implacável sobre o ensino privado e, em especial, sobre as escolas comunitárias, das quais só poucas resistiriam após o final do período. (DREHER, 2008). Este aspecto favoreceu que Aulas (escolas públicas), sob o controle do governo do Estado, no Rio Grande do Sul, fossem instituídas.

Se por um lado, a intensa preocupação dos governantes, tanto do governo gaúcho e posteriormente federal, entre 1930 a 1945, nas regiões coloniais (germânica e italiana), foi o de imprimir uma identidade nacional a partir da escola, este fato contribuiu para que em Lomba Grande as aulas isoladas fossem instaladas em diferentes localidades, ampliando atendimento dos filhos dos colonos, mesmo que fosse apenas para "aprender a escrever $o$ nome". (SCHERER, 2010).

Em 1933, precisamente em $1^{\text {o }}$ de setembro, a senhora Maria Hilda Scherer ${ }^{11}$, iniciou a "Aula Pública Mista no Morro dos Bois", no interior do bairro Lomba Grande (Novo Hamburgo/RS). Esta aula, ainda existe na localidade com o nome de Tiradentes.

A família da professora Maria Hilda Silva Scherer e seu esposo Carlos Arthur Scherer geraram três filhos: Enio Manuel Scherer ${ }^{12}$ (falecido), Vani Isabel Scherer e Sérgio José Scherer. O professor Sérgio casou-se com Érika Rönnau e tiveram quatro filhas: Márcia Regina Scherer Nunes ${ }^{13}$, Maristela Scherer Tavares, Maria Inês Scherer e Elisa Teresinha Scherer dos Santos.

A localidade do Morro dos Bois dista aproximadamente vinte quilômetros da sede do município. A origem do nome relaciona-se a lenda de que uma invernada ${ }^{14}$ de gado, que se encontrava sobre um dos muitos morros desceu morro abaixo, passando a ser conhecida como "Morro dos Bois". (PLANO, 1989). No século XVIII, em função da localidade estabelecer limite geográfico com Gravataí e Viamão, a "estrada de Morro dos Bois" servia de rota dos tropeiros que direcionavam o gado sulino para região sudeste do País. Sobre este período Souza e Fischer (2012, p.2), argumentam que a passagem dos tropeiros,

[...] de certo modo, também contribuíram para a história da cultura escolar deste lugar. Se por um lado, a presença portuguesa não foi capaz de constituir um lastro cultural tão forte quanto as raízes do status de vila (legado dos alemães na segunda metade do século XIX), a memória das "Aulas" sobreviveu à cronologia do tempo. 
As marcas culturais da presença germânica em nosso município registram os primórdios do que chamamos processo de escolarização pública. (SOUZA; FISCHER, 2012). Como em muitas comunidades no Brasil, que foram colonizadas pelos alemães, as vilas foram surgindo a partir da abertura de picadas que eram trilhas de acesso a uma propriedade. Com a instalação das famílias de colonos surgiram: os templos (católico ou luterano, às quais pertenciam imigrantes alemães); a escola ${ }^{15}$ (tradição trazida pelos imigrantes e que teria importância fundamental para o desenvolvimento do Brasil meridional); o cemitério; a residência do professor ou do padre/pastor e o salão de festas comunitárias. (DREHER, 2008).

Em cada picada também havia uma casa comercial, entreposto para o qual eram vendidos os excedentes de produção e através do qual se adquiriam bens não produzidos na comunidade. A casa comercial, muitas vezes conhecida por "venda" ou "armazém", era a porta de comunicação da picada com o mundo exterior, espaço para adquirir e circular informações e conhecimento.

Na década de 1930, como ainda não havia escola na localidade, o senhor Carlos Arthur Scherer construiu uma casa própria, que além de residência, funcionava como armazém e salão de baile. "Em dia de semana a casa da vó dividia espaço com o armazém e com a escola. O vô cuidava da roça e meu tio ajudava." (NUNES, 2010). Nesse sentido, é importante atentar para o que sinaliza os estudos de Viñao Frago e Escolano (2001) sobre os diferentes espaços em que os processos de escolarização se desenvolvem, inventam e processam saberes e apropriações.

Como rememora Sérgio, havia na localidade algumas aulas e instruções isoladas em que os familiares "pagavam algumas moedas pra ensinar os filhos deles". (SCHERER, 2010). A comunidade sentia a falta de uma escola. Então, Dona Hilda procurou a prefeitura municipal de São Leopoldo e solicitou autorização para iniciar uma escola pública que iniciou com 29 alunos, em 1933. A inauguração desta Aula, rapidamente absorveu os alunos da escola que existia anteriormente, pois

[...] existia uma escola [...] particular, de um tal de Manequim Inácio. Então, como esta pessoa não era muito bem quista, se envolveu em muitos casos de namoro [...] aí a minha mãe veio pra cá, quando eles vieram morar aqui, recém tinham casado. [...] vieram pra colocar o armazém, por causa do cemitério, porque era um dos cemitérios mais antigos. (SCHERER, 2010).

No contexto das práticas, tanto o professor Sérgio, quanto a professora Márcia referem-se à influência que Maria Hilda representou para eles. "Eu aprendi a dar aula porque realmente via a minha mãe dar aula. Aprendi a dar aula, como ela dava aula, pois eram cinco séries [...].". (SCHERER, 2010). Se o professor Sérgio, deu os primeiros passos na docência aos olhos da mãe, professora Hilda. Márcia iniciou sua trajetória docente, aos olhos do pai, da avó - e como lembra Daniel Nunes, esposo de Márcia - a docência foi constituindo-se nas permanências, na experiência, no saber fazer, sendo, fazendo:

A vó dela dava aula muito bem [...], era uma professora muito detalhista e ela se criou dentro da escola, da casa da vó dela, a vó dela dava aula com muito detalhe $[\ldots]$ poucas aulas dela eu assisti, mas quando o pai dela, $[\ldots]$ tava doente, ela dava aula [...] ela explicava [...] com clareza, então vem de família. (NUNES, 2010).

Esperava-se do professor primário, no contexto nacionalista, que desenvolvesse a educação das crianças pelo seu próprio exemplo moral de civilidade, pois o professor 
deveria ser o primeiro a ter em seu corpo as marcas de civilidade impressas, pelo exemplo, pela paciência e afetividade. (CUNHA, 2009). O professor, contido e recatado seria os representantes legítimos na constituição dos valores morais "[...] construtores da Nação [...] propagava [...] qualidades morais (boas maneiras, bons antecedentes, bons hábitos [...]) o que comporiam a figura do(a) professor(a) e dariam um sentido nobre à profissão docente". (CUNHA, 2009, p. 239).

Hilda, Sérgio e Márcia, professores primários, compõem o cenário docente que remete aspectos de práticas pedagógicas que associaram o magistério ao sentimento de "servir" ao público, a nação e construir uma "legião de soldados" para pátria. (FISCHER, 2005). Além disso, como rememora Sérgio, havia pretensão de imprimir uma postura higiênico-sanitarista,

Quando a minha mãe veio pra cá, ela contava: [...] o pessoal era daquele tipo assim, vinham fumando e escarravam no chão. A minha mãe veio, foi indo, indo, e ensinando... que tirou aquele hábito do pessoal. [...] convencendo os alunos, os pais [...]. (SCHERER, 2010).

Cunha (2009) complementa que a Igreja foi uma das principais aliadas da Escola Primária para divulgar os preceitos de civilidade e inspirar o nacionalismo cívico. Pretendia-se levar o Brasil a modernidade moldando os sujeitos e educando-os condutas, boas maneiras, regras e comportamento ordeiro, cosmopolita para que tivessem a conduta esperada pela "boa sociedade". Sergio ainda reforça que tratavam o aluno

[...] como um filho. [...] vinha criança de Lomba Grande [se refere ao centro do bairro] para ter aula aqui. Eu tinha fama de ser durão - alunos rebeldes comigo não tinha. Pra ti ver, eu não tenho notícia de que exaluno foi preso, ou é bandido. [...] Eu já te falei, educar, tratar bem, mas com dureza. A Cléris Becker [Diretora do Grupo Escolar Madre Benícia - atual Instituto de Educação Madre Benícia] veio pra mim, quando eu era diretor do colégio e disse: - Sérgio eu tenho gosto de receber aluno do teu [...]. (SCHERER, 2010).

O "entusiasmo cívico" esteve incorporado às atribuições daqueles que desejassem exercer o magistério. (WERLE; METZLER, 2009). O sentido filosófico da profissão expresso nas memórias de práticas dos sujeitos entrevistados revela que a docência foi por eles interpretada, acima de tudo como vocação. Além disso, as narrativas expressaram que havia uma "sagrada missão ao magistério" e que essa sublime missão tinha nos seus professores a responsabilidade, não só pelo preparo de futuros cidadãos para a pátria, mas também de futuros herdeiros para o céu. (FISCHER, 2005). Portanto, civilizar associava-se a constituir uma cultura moderna e homogeneizada para a população.

\section{Considerações finais}

A historiografia da educação brasileira se ressente de estudos mais aprofundados sobre essas instituições. (SOUZA, 2006). As Escolas Isoladas, instaladas nas zonas rurais e nos bairros populares, foram responsáveis pela escolarização de uma significativa parcela da população brasileira. No entanto, foi a Escola Isolada, multisseriada e unidocente, a que permaneceu sendo, durante muitas décadas do século XX, o tipo predominante de escola pública primária no Estado.

Na primeira metade do século XX a educação aparece como um dispositivo tutelar para melhoria das condições de vida do proletário urbano e rural. A política de Vargas, tanto no discurso quanto na legislação pretendia colocar o sistema educacional a serviço da 
implantação de um governo autoritário. Dessa forma, a concepção da educação seria um problema nacional, através da ligação entre educação e saúde com ênfase na educação moral. (BAIA HORTA, 2010).

A análise das memórias permite constatar que os hábitos e costumes dos moradores da localidade do Morro dos Bois foram sendo ressignificado a partir da intervenção e presença da escola. Mesmo que este estudo seja inicial, constata-se que a evidência das Aulas superou a dos Grupos Escolares. Nas comunidades rurais, a escola isolada, foi indispensável para se pensar a concretização do projeto republicano da escola pública no Brasil, representando a forma possível para se aprender a "ler, escrever e contar". (FARIA FILHO, 2004).

\section{Referências}

ALMEIDA, Dóris Bittencourt. Memórias da rural: narrativas da experiência educativa de uma escola normal rural pública (1950-1960). 2007. 272 f. Tese (Doutorado em Educação) -- Programa de Pós-Graduação da Faculdade de Educação, Universidade Federal do Rio Grande do Sul, Porto Alegre, RS.

Vozes esquecidas em horizontes rurais: histórias de professores. 2001. $245 \mathrm{f}$. Dissertação (Mestrado em Educação) -- Programa de Pós-Graduação da Faculdade de Educação, Universidade Federal do Rio Grande do Sul, Porto Alegre, RS, 2001.

ALMEIDA, Jane Soares de. Apresentação. In: SAVIANI, Dermeval et al. O legado educacional do século XX no Brasil, 2a. Ed. Campinas, SP: Autores Associados, 2006, p. $1-9$.

AMADO, Janaína. O grande mentiroso: tradição, veracidade e imaginação em História Oral. História, São Paulo, 14, 1995, p. 125-136.

BAIA HORTA, José Silvério. A Política Educacional no Estado Novo. In: SAVIANI, Dermeval. (Org.). Estado e políticas educacionais na história da educação brasileira. Vitória: EDUFES, 2010, p. 281-316.

BALANDIER, Georges. O contorno: poder e modernidade. Rio de Janeiro: Bertrand Brasil, 1997.

BURKE, Peter. O que é história cultural? Trad. Sérgio Góes de Paula. Rio de Janeiro: Jorge Zahar Ed, 2005.

CARDOSO, Tereza Fachada Levy. As Aulas Régias no Brasil. In: STEPHANOU, Maria; BASTOS, Maria Helena Câmara. (Org.) História e memórias da educação no Brasil, vol. 1: século XVI-XVIII. Petrópolis, RJ: Vozes, 2009, p. 179-191.

CHARTIER, Roger. À beira da falésia: a história entre incertezas e inquietude/ trad. RAMOS, Patrícia Chittoni, Porto Alegre: Ed. Universidade/UFRGS, 2002.

CUNHA, Maria Tereza Santos. Saberes impressos escritas da civilidade e impressos educacionais. (Década de 1930 a 1960). In: YAZBECK, Carolina; ROCHA, Marlos Bessa Mendes da. (Orgs.). Cultura e História da Educação: intelectuais, legislação, cultura escolar e imprensa, Juiz de Fora: Editora UFJF, 2009, p. 233-251.

CURY, Cláudia Engler. Desafios da Pesquisa com Cultura Escolar na Documentação da Parahyba Oitocentista. In: VIDAL, Diana Gonçalves.; SCHWARTZ, Cleonara Maria. (Org.). História das Culturas Escolares no Brasil. Vitória: EDUFES, 2010, p. 37-58. 
DREHER, Martin Norberto. Breve história do ensino privado gaúcho. São Leopoldo: Oikos, 2008.

FARIA FILHO, Luciano Mendes de. Processos de escolarização no Brasil: algumas considerações e perspectivas de pesquisa. In: MENEZES, Maria Cristina (Org.). Educação, Memória, História: possibilidades, leituras. Campinas: Mercado de Letras, 2004. p. 521-544.

FERRI, Cássia. Classes multisseriadas: que espaço escolar é esse? 1994. 161 f. Dissertação (Mestrado em Educação) -- Programa de Pós-Graduação em Educação, Universidade Federal de Santa Catarina, Santa Catarina, SC,1994.

FERREIRA, Aurélio Buarque de Holanda. Mini Aurélio: dicionário da língua portuguesa. 8a. ed. Curitiba: Positivo, 2010.

FISCHER, Beatriz Terezinha Daudt. Professoras: histórias e discursos de um passado presente. Pelotas: Seiva, 2005.

GOMES, Dinóra Antonina. Rastros que não se apagam: vida - história e árvore genealógica de Adriano Antônio Gomes. [S.l: s.n., 2000].

GHIRARDELli JUNIOR, Paulo. História da Educação. São Paulo: Cortez, 2009.

GRAZZIOTIN, Luciane Sgarbi Santos. Memórias recompondo tempos e espaços da educação: Bom Jesus/RS (1913-1963). 2008. 232 f. Tese (Doutorado em Educação) -Programa de Pós-Graduação em Educação, Pontifícia Universidade Católica do Rio Grande do Sul, Porto Alegre, RS, 2008.

HALBWACHS, Maurice. A memória coletiva. São Paulo: Ed. Centauro, 2006.

KREUTZ, Lúcio. Escolas comunitárias de imigrantes no Brasil: instâncias de coordenação e estruturas de apoio. Revista brasileira de Educação, Rio de Janeiro, v. 1, n. 15, 2001, p. 159177.

LUCHESE, Terciane Ângela.; KREUTZ, Lúcio. Das Escolas de Improviso às Escolas Planejadas: Um Olhar Sobre os Espaços Escolares da Região Colonial Italiana, Rio Grande do Sul. Revista Brasileira de História da Educação, Campinas: São Paulo, v. 12, n. 2(29), p. 45-75, maio/ago. 2012.

NOVO HAMBURGO. Decreto n. 4, de 16 de outubro de 1952. Regimenta Escolas Municipais. Novo Hamburgo-RS, 1952.

NUNES, Márcia Scherer. . Entrevista oral sobre a trajetória de vida e docente em classes multisseriadas em Lomba Grande. Novo Hamburgo, 21 de abril de 2010 e 03 de maio de 2010. Ex-professor e diretor de Escolas Municipais de Lomba Grande - Novo Hamburgo. Entrevista concedida a AUTOR.

NUNES, Zeno Cardoso; NUNES, Rui Cardoso. Dicionário de regionalismo do Rio Grande do Sul. 10. ed. Porto Alegre: Martins Fontes, 2003.

O 5 DE ABRIL. Prefeitura Municipal. Ano XVI, n. 46, 12 de fev. de 1943., p. 4.

OLIVEIRA, Leda Maria Leal de. Memórias e experiências: desafios da investigação histórica. In: FENELON, Déa Ribeiro et al. Muitas memórias, outras histórias. São Paulo: Olho D'água, p. 263- 281, 2004. 
PESAVENTO, Sandra Jathay. Introdução. In: PESAVENTO, Sandra Jathay; SANTOS, Nádia Maria Weber; ROSSINI, Miriam de Souza. Narrativas, imagens e práticas sociais: percursos em história cultural. Porto Alegre, RS: Asterisco, 2008, p. 11-19.

PIMENTEL, Alessandra. O método da análise documental: seu uso numa pesquisa historiográfica. Cadernos de pesquisa, São Paulo, n. 114, p.179-195, nov. 2001.

PLANO Curricular Global. EMEF Tiradentes (1989). Rascunho do Plano Curricular Global. Documento escrito a punho pelo professor Sérgio José Scherer. Localizado em 12 de dezembro de 2102. Arquivo Passivo da EMEF Tiradentes, 1989.

RAMALHO, Maria Nailde Martins. Na Roça, na raça...Eu me tornei professor: um estudo sobre a formação docente de professores de classes multisseriadas no Norte de Minas Gerais e Vale do Jequitinhonha. In: ENCONTRO NACIONAL DE PESQUISA EM EDUCAÇÃO DO CAMPO, 3., 2010, Brasília, DF. Trabalhos apresentados... Brasília: UNB, 2010. Disponível em <www.encontroobservatorio.unb.br/arquivos/artigos/4.pdf>. Acesso em: 12 set. 2010.

REGISTRO dos Funcionários Municipais. (Livro ponto). Livro ponto dos funcionários municipais de Novo Hamburgo (1945-1955), 256 p., 1945. Localizado no Arquivo Público Municipal de Novo Hamburgo, 1945.

RIBEIRO, Marlene. Pedagogia da alternância na educação rural/do campo: projetos em disputa. Educação e Pesquisa, São Paulo, v. 34, n. 1, p. 27-46, jan./abr. 2008

ROCHA, Silvio. (Org.). Escola cidadã em Novo Hamburgo: participação, qualidade e aprendizagem. Novo Hamburgo: Prefeitura Municipal, 2012.

SAVIANI, Dermeval. O Estado e a promiscuidade entre o público e o privado na história da educação brasileira. In: SAVIANI, Dermeval. (Org.). Estado e políticas educacionais na história da educação brasileira. Vitória: EDUFES, 2010, p. 17-44.

SCHERER, Sérgio José. Entrevista oral sobre a trajetória de vida e docente em classes multisseriadas em Lomba Grande. Novo Hamburgo, 21 de abril de 2010 e 03 de maio de 2010. Ex-professor e diretor de Escolas Municipais de Lomba Grande - Novo Hamburgo. Entrevista concedida a AUTOR.

SOUZA, José Edimar de. Memórias de professores: histórias de ensino em Novo Hamburgo/RS (1940-2009). Porto Alegre: Evangraf, 2012.

; FISCHER, Beatriz T. Daudt. Memórias do ensino em Novo Hamburgo: documentos e acervos (1940-2009). NH na Escola, Novo Hamburgo, p. 2-2, 25 out. 2012.

.; GRAZZIOTIN, Luciane S. Santos. Memórias evocadas: imagens recompondo as aulas isoladas em Novo Hamburgo/RS (1913 a 1952). Aedos: Revista do Corpo Discente do Programa de Pós-Graduação em História da UFRGS (Online), v. 4, p. 652 674, 2012.

SOUZA, Rosa Fátima de. Lições da escola primária. In: SAVIANI, Dermeval; ALMEIDA, Jane Soares de; SOUZA, Rosa Fátima de; VALDEMARIN, Vera Teresa. 2 ${ }^{\mathrm{a}}$. Ed. O legado educacional do século XX no Brasil. Campinas, SP: Editores Associados, 2006, p. 111161.

STEPHANOU, Maria. Nem uma coisa, nem outra ou nenhumas. Re invenções e reminiscências escolares. A modo de prefácio. In: FISCHER, Beatriz T. Daudt. Tempos de escola - Memórias (Org.) São Leopoldo: Oikos; Brasília: Liber Livro, 2011, p. 11-16. 
THOMPSON, Paul. A voz do passado: historia oral. Trad. Lólio Lourenço de Oliveira. Rio de Janeiro: Paz e Terra, 1992.

THOMSON, Alistair. Recompondo a memória: questões sobre a relação entre a História Oral e as memórias. Projeto História, São Paulo, 15, abr. 1997, p. 51-84.

VIÑAO FRAGO, Antônio.; ESCOLANO, Agustín. Currículo, espaço e subjetividade: a arquitetura como programa. Tradução Alfredo Veiga-Neto. 2a . ed. Rio de Janeiro: DP\&A, 2001.

WERLE, Flávia Obino Corrêa. O nacional e o local: ingerência e permeabilidade na educação brasileira. Bragança Paulista: Ed. Universidade São Francisco, 2005.

\section{Notas}

${ }^{1}$ Uma primeira versão deste texto foi publicada nos Anais do VII Congresso Brasileiro de História da Educação - SBHE, 2013, Cuiabá - Mato Grosso.

${ }^{2}$ Graduado em História, mestre e doutorando em Educação na UNISINOS, com bolsa CAPES/Proex. Especialista em Educação na Fundação Escola Técnica Liberato Salzano Vieira da Cunha, de Novo Hamburgo. Orientado da profa. Dra. Luciane S. Santos Grazziotin.

${ }^{3}$ A professora Márcia Scherer Nunes e o professor Sérgio José Scherer integram o grupo de professores que foram entrevistados para escrita da dissertação de mestrado em educação na UNISINOS, sob orientação da professora Dra. Luciane S. Santos Grazziotin e co-orientação da professora Dra. Beatriz T. Daudt Fischer. São identificados neste estudo considerando que os mesmos assinaram termo de consentimento autorizado.

${ }^{4}$ Este trabalho não pretende discutir trajetórias para o campo ou no campo como tratam, por exemplo, Ribeiro (2008), portanto (zona, espaço, meio, área) é lugar de contexto em que as memórias e práticas emergiram e foram analisadas. Sobre este assunto consultar também Almeida (2001; 2007). A literatura recente sobre o tema mostra a emergência do conceito de educação do campo, que se contrapõe à visão tradicional de educação rural.

${ }^{5}$ Utilizo propositalmente a expressão "remanescente", no sentido que é o que "resta", o que "sobrou", os vestígios das práticas docentes multisseriadas de instituições escolares públicas municipais em Novo Hamburgo. (FERREIRA, 2010, p.654). Com o termo, pretende-se enfatizar o processo histórico e de constituição da organização comunitária que como em Lomba Grande, em diferentes localidades do nosso país garantiram, mesmo que de modo rudimentar, a instrução mínima de escolarização entre os séculos XIX e XX.

${ }^{6}$ Quem responde pela gestão da EMEF Tiradentes é a diretora na EMEF Conde D’Eu - localizada no Quilombo.

${ }^{7}$ Ramalho (2010) identificou 81 mil escolas brasileiras com regime de trabalho multisseriado em 2003. Um estudo mais denso sobre a escola multisseriada na região sul, em Santa Catarina consultar a dissertação de mestrado de Cássia Ferri (1994).

${ }^{8}$ Na pesquisa desenvolvida no curso de mestrado (2010-2011), caracterizo o período de 1940 a 1970 como "primeiros tempos" cuja docência esteve vinculada a ideia de tradição de família, entrecruzada à representação docente como um "apostolado missionário", sob forte influência da Igreja cristã católica. Além disso, as trajetórias amarraram práticas que relacionam contexto local e história institucional. (SOUZA, 2012).

${ }^{9} \mathrm{O}$ registro mais antigo de uma Aula Pública, localizado até o presente momento, data 1863, com título de Aula Pública de Lomba Grande. Havia no início do século XX, as seguintes aulas: Aula Pública Mista Federal; Aula da Comunidade Evangélica de Lomba Grande; Aula da Comunidade Católica de Lomba Grande. Estas aulas formaram as Aulas Reunidas em 1939 e posteriormente o Grupo Escolar de Lomba Grande em 1942 (atual Instituto Estadual de Educação Madre Benícia). Todas localizadas na região central do bairro. (SOUZA; GRAZZIOTIN, 2012). Em novo Hamburgo, as instituições escolares recebiam denominações patronímias. Os patronos, de acordo com publicação de decreto municipal no jornal O 5 de 
abril de 12 de fevereiro de 1943, consta, associam o número da Aula ao patrono: "Pela Portaria n. 24 foram designados, pelo Senhor prefeito, patronos e respectivos números para todas as aulas municipais. [...] as aulas 11-18 ainda não tiveram denominações próprias, sendo a 'Roque Gonzales' reaberta, a pedido dos moradores do Travessão, pois a mesma estava fechada a um ano. A Portaria em apreço e a seguinte: 10 de fevereiro de 1943. Portaria n. 24 [...] 11 - Tiradentes - $3^{\circ}$ Distrito - Morro dos Bois; 12 - Rui Barbosa - $3^{\circ}$ Distrito - Santa Maria do Butiá; 13 - José de Anchieta - São João do Deserto - $3^{\circ}$ Distrito; 14 - Bento Gonçalves - $3^{\circ}$ Distrito - Taimbé; 15 - General Ozório - $3^{\circ}$ Distrito - Barrinha; 16 - Conde D'Eu - $3^{\circ}$ Distrito - Quilombo do Sul; 17 - Princeza Izabel - $3^{\circ}$ Distrito - Quilombo do Norte [...]". (Jornal O 5 de Abril, 12 de fevereiro de 1943, p.4). Observa-se, que em 1943, no interior do bairro havia pelo menos sete aulas.

${ }^{10}$ A abertura cultural no Brasil deu-se a partir do reformismo pombalino, com a criação de Aulas Régias ${ }^{10}$. A consequência imediata ligada à escolarização refere-se ao fechamento dos colégios jesuítas e a transferência do controle de suas missões para o Estado. (SAVIANI, 2010). Para Cardoso (2009) não era necessário um edifício escolar para que a escola existisse, esse aspecto aparecerá, principalmente, com o surgimento dos Grupos Escolares. Luchese e Kreutz (2012) atribuem a expressão "escolas de improviso", para a forma artesanal de organização das comunidades, no caso deste estudo, das primeiras escolas em Lomba Grande. Kreutz (2009) argumenta que a "casa-escola" ou "escolas comunitárias", guarda não apenas herança de aspectos das Aulas Régias, do ponto de vista cultural, elas representam uma possibilidade de constituição de identidade.

${ }^{11}$ As páginas 51 e 52 do Livro ponto dos funcionários municipais de Novo Hamburgo registram aspectos importantes sobre a trajetória profissional de Hilda. (REGISTRO, 1945). Ela nasceu em 26 de julho de 1912, em Lomba Grande. Filha de uma das famílias pioneiras do lugar: Luiz Albino da Silva e Adelina da Silva. (GOMES, 2000). “Aprovada em concurso no município de São Leopoldo [...] Apresentou certidão de tempo de serviço do município de São Leopoldo no qual consta haver iniciada suas atividades [...] a $1^{\circ}$ de setembro de 1933, as quais desempenhou até dezembro de 1939, tendo com a anexação, à este município, o distrito de Lomba Grande passou a servir à este município. [...]. (REGISTRO, 1945, p. 51-52).

${ }^{12}$ O professor Ênio foi docente na Escola Tiradentes entre 1944 a 1948. Falecido em 1949. A professora Vani entre 1952 a 1955. Professor Sérgio entre 1960 a 1995. (PLANO, 1989).

${ }^{13}$ Professora Márcia foi docente na EMEF Tiradentes entre 1974 a 2010. E a professora Elisa atualmente é docente na EMEF Tiradentes.

14 “Grande extensão de campo, cercado. Nas estâncias, geralmente, há diversas invernadas: para criar, para engordar, para cruzamentos de raças, para desterneirar vacas, etc.” ( NUNES.; NUNES, 2003, p. 247).

${ }^{15}$ Mais detalhes sobre a casa-escola ou escolas comunitárias nas regiões germânicas ver Kreutz (2001).

$\begin{array}{ll}\text { Recebido em } & \text { janeiro-13 } \\ \text { Aprovado em } & \text { março-13 }\end{array}$

